\title{
Interactive test to categorize metamorphopsia
}

\author{
Daniela Claessens ${ }^{*}$ and Ronald V Krueger ${ }^{2}$ \\ ${ }^{1}$ Augenheilkunde Lindenthal, Cologne, Germany \\ ${ }^{2}$ App4eyes GmbH \& Co. KG, Duesseldorf, Germany
}

\begin{abstract}
Aims: In this observational study metamorphopsia categorization using the computer-based test MacuFix was performed in eyes with and without maculopathy.

Methods: In all eyes spectral domain optical coherence tomography and Amsler Test were performed, best corrected visual acuity (BCVA) was determined and the App MacuFix was used defining a class reflecting a magnitude difference.

Results: The study included 69 eyes of 23 women and 25 men. The average age was $70 \pm 11$ years. Inclusion criterion was maculopathy in at least one eye. Exclusion criterion was BCVA lower than 20/200. The average BCVA was 20/30.42 eyes perceived metamorphopsia in the Amsler grid, 27 did not. The group with maculopathy consisted of 57 eyes: diagnoses were early age related macular degeneration (AMD) in eight, intermediate AMD in 20, late AMD in 9, diseases of the vitreoretinal interface in 11, non-AMD macular edema in 9 eyes. 12 eyes had no macular pathology. The smallest correctly detected magnitude difference measured by MacuFix was on average 2.12 for eyes perceiving metamorphopsia (standard deviation $\mathrm{SD}= \pm 1.29)$ and 1.15 for eyes not perceiving metamorphopsia $(\mathrm{SD}= \pm 0.36)$. The difference between those two groups was statistically highly significant $(\alpha=0.05,2$-sided t-test for unrelated samples, $\mathrm{p}<0.001$; confidence interval $\mathrm{CI}(0.54 ; 1.40))$. Eyes with macular edema $(\mathrm{n}=14)$ had a mean magnitude difference of $2.79(\mathrm{SD}= \pm 1.47)$. Eyes without maculopathy had a mean magnitude difference of $1.08(\mathrm{SD}= \pm 0.28)$. The difference between eyes with macular edema and eyes without maculopathy was statistically significant $(\alpha=0.05 ; \mathrm{p}<0.05 ; \mathrm{CI}(0.81 ; 2.60))$.
\end{abstract}

Conclusions: In this study the metamorphopsia measurements with MacuFix differed significantly between eyes with and without metamorphopsia. Eyes with macular edema were characterized by higher values in MacuFix Class compared to eyes with normal macula.

\section{Introduction}

Diseases of the macula can lead to a disturbed visual impression (metamorphopsia) [1]. Implying optical coherence tomography (OCT) it was possible to attribute metamorphopsia to changes in the photoreceptor level $[2,3]$ but neurological influences are also discussed [4]. Previous methods for metamorphopsia detection and monitoring [5-7] were mostly qualitative or semi-quantitative. The Amsler Grid [8] provides simple and fast qualitative assessment of visual function in the central $10^{\circ}$ of the visual field with limited sensitivity due to its supra threshold nature [9,10]. Morphision [6] is a semi-quantitative paper-based test which delivers a categorization of metamorphopsia by comparing the perception of images presented to the eye perceiving metamorphopsia with the fellow healthy eye. To classify the severity of metamorphopsia M-CHARTS was developed by Matsumoto et al. As the above mentioned tests may be limited by "filling in" [11] or "visual crowding" [12], procedures based on preferential hyperacuity perimetry were implemented [13-15]. A quantitative metamorphopsia measurement based on the Amsler Grid was made possible in 2015 with the development of the software "AMD - A Metamorphopsia Detector" " [16-22]. The users observe monocularly with appropriate near correction white horizontal or vertical lines, respectively, displayed on the black background of the computer screen. The patients monocularly fixate the central white dot and straighten the lines that they perceive to be distorted by moving the mouse wheel. The Metamorphopsia Index is determined using the magnitude, distance from the central fixation point and area that are measured by the software. Based on this software, the app MacuFix was developed to provide a low-threshold, cost-effective option. This study was performed to investigate whether MacuFix can distinguish between eyes with and without metamorphopsia and the one hand and between eyes with and without maculopathy on the other hand.

\section{Materials and methods}

An observational pilot study was performed from June to October 2019 in a private practice. The patients had been provided with written information about the study which they read prior to consenting to participate in the study. All patients signed informed consent based on the Declaration of Helsinki prior to the study. Eyes with and without maculopathy were examined by spectral domain optical coherence tomography (SD-OCT, CIRRUS ${ }^{\mathrm{ra}} \mathrm{HD}$-OCT, Carl Zeiss Meditec) and Amsler Test, best corrected visual acuity (BCVA) and near correction for the computer screen were determined. The software MacuFix was used on a personal computer. The exclusion criterion was best corrected visual acuity less than 20/200. Statistical analyses were performed with the statistical software "R" (Version 3.6.1., R Foundation, R Core Team: A Language and Environment for Statistical Computing. R Foundation for Statistical Computing, Vienna, Austria. http://www.R-project.org).

The App MacuFix displays four grids, each 4 degrees large. The grids show distorted lines, one grid standing out due to higher magnitudes

${ }^{*}$ Correspondence to: Daniela Claessens, Augenheilkunde Lindenthal, Duerener Str. 251, Cologne, Germany, E-mail: daniela.claessens@gmx.de

Key words: age related macular degeneration, metamorphopsia, metamorphopsia measurement, interactive test

Received: March 02, 2021; Accepted: March 19, 2021; Published: March 25, 2021 
as shown in Figure 1. The magnitudes are calculated by the program AMD-A Metamorphopsia Detector [23]. While wearing appropriate near correction, the patients monocularly select the grid they perceive most distorted. The response speed per scene defines the length of the following scenes. A time bar shows the respondent the time available. If no selection is made, the selection is evaluated as incorrect. At least 10 scenes with varying magnitude differences are shown to evaluate the smallest detectable magnitude difference. This process takes about one minute per eye. An algorithm determines the smallest detectable magnitude difference displayed as MacuFix class. Results are displayed and stored for monitoring. If used on a smart phone encrypted results can be sent to the ophthalmologist for monitoring or feedback, e.g. invitation for a re-examination.

\section{Results}

The study included 69 eyes of 23 women and 25 men. The average age was $70 \pm 11$ years. Inclusion criterion was OCT-documented maculopathy in at least one eye. Exclusion criterion was BCVA worse than 20/200. The average BCVA was 20/30. The group with maculopathy consisted of 57 eyes: diagnoses were early age related macular degeneration (AMD) in 8, intermediate AMD in 20, late AMD in 9 , diseases of the vitreoretinal interface in 11, non-AMD macular edema in 9 eyes. Twelve eyes had no macular pathology. 42 eyes perceived metamorphopsia when tested with the Amsler Grid, 27 did not see any metamorphopsia in the Amsler Grid.

The smallest correctly detected magnitude difference was on average 2.12 for eyes perceiving metamorphopsia in the Amsler Grid (standard deviation $\mathrm{SD}= \pm 1.29$ ) and 1.15 for eyes not perceiving metamorphopsia

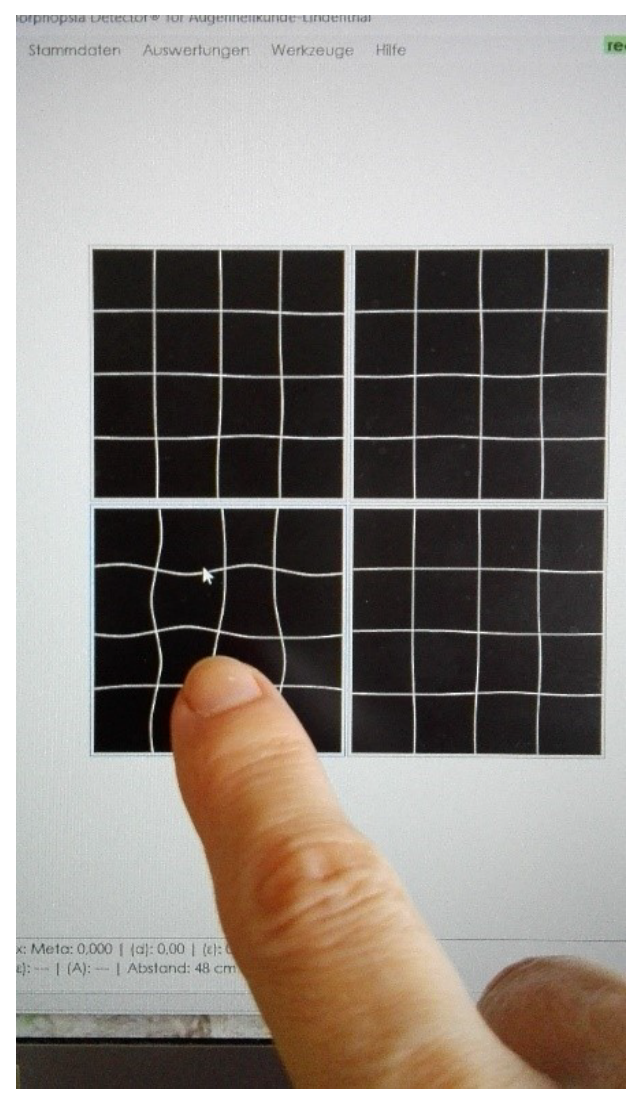

Figure 1. App MacuFix: patient selecting a grid on a touch device
$(\mathrm{SD}= \pm 0.36)$. The difference in magnitude difference between those two groups was statistically highly significant $(\alpha=0.05,2$-sided $t$-test for unrelated samples, $\mathrm{p}<0.001$; Confidence interval CI $(0.54 ; 1.40)$ ).

Eyes with macular edema $(n=14)$ had a mean magnitude difference of 2.79 ( $\mathrm{SD}= \pm 1.47$ ), whereas eyes without maculopathy had a mean magnitude difference of 1.08 ( $\mathrm{SD}= \pm 0.28$ ). The difference between eyes with macular edema and eyes without maculopathy was statistically significant $(\alpha=0.05 ; \mathrm{p}<0.05 ; \mathrm{CI}(0.81 ; 2.60))$.

\section{Discussion}

In this study eyes with macular disease, especially those with macular edema were characterized by higher values in MacuFix class compared to eyes with normal macula.

\section{Limitations}

Including both eyes of some of the participants might imply bias and cooperation of the patients as well as their understanding of the test can influence the test results.

\section{Functional diagnostic tools in macular diseases}

The Amsler grid does not allow for the quantification of the severity of metamorphopsia. Additional limitations are a missing documentation possibility, its lack of fixation control, low sensitivity due to the "crowding effect" and its confined ability to detect scotoma, especially when these scotoma are small and are not close to the fovea, an effect called the "filling-in-phenomenon". The Morphision test can be used to assess the severity of metamorphopsia, however its application is limited because it presupposes a healthy fellow eye. M-CHARTS tests for metamorphopsia in the horizontal or vertical meridian only. By increasing the number of lines, an expansion of up to $10^{\circ}$ from the central fixation point is possible leading to a prolongation of the test. M-CHARTS is unable to specify the region of metamorphopsia and cannot be used by patients with best corrected visual acuity lower than 20/100 or large (para-) central scotoma. ForeseeHome (Notal Vision Ltd, Tel Aviv, Israel) is based on hyperacuity and covers $14^{\circ}$ of the central visual field. The AREDS2-HOME study [24] found that due to visual field defects or problems adapting to the testing device about $20 \%$ of patients were not able to use ForeseeHome successfully.

Coco-Martin et al. [25] found a moderate reliability for the colour perimetry technique to assess in vivo macular pigment optical density in eyes with age-related macular degeneration with regard to the intra-session repeatability and inter-examiner reproducibility. Welker and co-authors documented a good intrasession test-retest reliability of mesopic and dark-adapted microperimetry in patients with intermediate age-related macular degeneration and age-matched controls and deduced that the instrument was a reliable tool in this patient group [26].Visual acuity is a standardizable parameter and the most widely used test to describe visual function. According to a crosssectional study [27] ETDRS (Early Treatment Diabetic Retinopathy Study) - charts render a high repeatability. In eyes with AMD, however, the intersession visual acuity measurements revealed considerable variability $[28,29]$.

Available applications for the quantification of metamorphopsia are in a range between time-consuming, cost-intensive tests that place a high demand on the patient on the one hand and easily feasible tests with limited validity on the other. The results of this pilot study motivate us to address the question of reliability, sensitivity and the usability of the app MacuFix, currently examined in a study approved by the ethics commission of the North Rhine Medical Council. Further studies shall 
inquire if this software can improve compliance and adherence in the management of macular diseases.

\section{Disclosures}

This research did not receive any specific grant from funding agencies in the public, commercial, or not-for-profit sectors. DC and RK are patent owners of AMD - A Metamorphopsia Detector ${ }^{\circledR}$ software and have a financial interest in app4eyes.

\section{References}

1. Amsler M (1949) Quantitative and qualitative vision. Trans Ophthalmol Soc UK 69: 397-410.

2. Watanabe A, Arimoto S, Nishi O (2009) Correlation between metamorphopsia and epiretinal membrane optical coherence tomography findings. Ophthalmology 116 : 1788-1793.

3. Okamoto F, Sugiura Y, Okamoto Y, Hiraoka T, Oshika T (2012) Associations between metamorphopsia and foveal microstructure in patients with epiretinal membrane. Invest Ophthalmol Vis Sci 53: 6770-6775.

4. Wiecek E, Lashkari K, Dakin SC, Bex P (2014) Novel quantitative assessment of metamorphopsia in maculopathy. Invest Ophthalmol Vis Sci 56: 494-504. [Crossref]

5. Midena E, Vujosevic S (2015) Metamorphopsia: An overlooked visual symptom. Ophthalmic Res 55: 26-36. [Crossref]

6. Ugarte M, Shunmugam M, Laidlaw DAH, Williamson TH (2013) Morphision: a method for subjective evaluation of metamorphopsia in patients with unilateral macular pathology (i.e., full thickness macular hole and epiretinal membrane). Indian J Ophthalmol 61: 653-658.

7. Bouwens MD, Meurs JCV (2003) Sine Amsler Charts: A new method for the follow-up of metamorphopsia in patients undergoing macular pucker surgery. Graefes Arch Clin Exp Ophthalmol 241: 89-93.

8. Amsler M. Die Untersuchung des qualitativen Sehens mit dem quadratischen Netz. Anweisung zum Gebrauch der Testtafeln. 1958: Theodore Hamblin LTD.

9. Crossland M, Rubin G (2007) The Amsler chart: absence of evidence is not evidence of absence. Br J Ophthalmol 91: 391-393. [Crossref]

10. Schuchard RA (1993) Validity and interpretation of Amsler grid reports. Arch Ophthalmol 111: 776-780. [Crossref]

11. Achard OA, Safran AB, Duret FC, Ragama E (1995) Role of the completion phenomenon in the evaluation of Amsler grid results. Am J Ophthalmol 120: 322-329.

12. Parkes L, Lund J, Angelucci A, Solomon JA, Morgan M (2001) Compulsory averaging of crowded orientation signals in human vision. Nat Neurosci 4: 739-744.

13. Klatt C, Bunse A, Roider J (2004) Erste klinische Erfahrungen mit PreView PHP (Zeiss) zur Quantifizierung von Metamorphopsien bei Erkrankungen der Makula. Klin Monatsbl Augenheilkd, 221(V49).

14. Chew EY, Clemons TE, Bressler SB, Elman MJ, Danis RP et al. (2014) Randomized trial of a home monitoring system for early detection of choroidal neovascularization home monitoring of the Eye (HOME) study. Ophthalmology 121: 535-544.
15. Wang YZ, Yu-Guang He, Mitzel G, Zhang S, Bartlett M, et al. (2013) Handheld shape discrimination hyperacuity test on a mobile device for remote monitoring of visual function in maculopathy. Invest Ophthalmol Vis Sci 54: 5497-5505. [Crossref]

16. Claessens D, Krüger R (2015) AMD-A metamorphopsia detector. Invest Ophthalmol Vis Sci 56: 4109.

17. Claessens D, Krüger R (2017) Three dimensions of quantitative metamorphopsia measurement - do disease specific patterns exist?, in ARVO. Denver.

18. Claessens D (2018) Dynamics of metamorphopsia characteristics during progression from intermediate to advanced age-related macular degeneration. Invest Ophthalmol Vis Sci 59: 2375.

19. Claessens D, Schuster AK (2019) longitudinal analysis of metamorphopsia measurement and its relation to change in drusen size and volume in intermediate agerelated macular degeneration. Invest Ophthalmol Vis Sci 60: 3474.

20. Claessens D, SchusterAK (2019) Korrelation derquantitativen Metamorphopsiemessung und der zentralen Netzhautdicke bei diabetischem Makulaodem und altersassoziierter exsudativer Makuladegeneration. Klin Monbl Augenheilkd 236: 877-884.

21. Krüger R, Claessens D (2017) Metamorphopsia measurement with AMD - A Metamorphopsia Detector ${ }^{\circledR}$ as a patient reported outcome (PRO). Invest Ophthalmol Vis Sci 58: 1522.

22. Claessens D (2016) Pro AMD Patient reported outcome documented by AMD - A M etamorphopsia Detector®. Invest Ophthalmol Vis Sci 57: 31 .

23. Claessens D, Schuster AK (2019) Correlation of quantitative metamorphopsia measurement and central retinal thickness in diabetic macular edema and age-related exsudative macular degeneration. Klin Monbl Augenheilkd 36: 877-884.

24. Domalpally A, Clemons TE, Bressler SB, Danis RP (2019) Michael ElmanImaging characteristics of choroidal neovascular lesions in the AREDS2-HOME Study: Report Number 4. Ophthalmol Retina 3: 326-335. [Crossref]

25. Coco-Martín RM, Pichel-Mouzo M, Fernández I, Plata-Cordero M, Lopez-Miguel A (2019) Reliability of colour perimetry to assess macular pigment optical density in age-related macular degeneration. Eur J Ophthalmol 1120672119870362. [Crossref]

26. Welker SG, Pfau M, Heinemann M, Schmitz-Valckenberg S, Holzet FG, et al. (2018) Retest reliability of mesopic and dark-adapted microperimetry in patients with intermediate age-related macular degeneration and age-matched controls. Invest Ophthalmol Vis Sci 59: AMD152-AMD159.

27. Chaikitmongkol V, Nanegrungsunk O, Patikulsila D, Ruamviboonsuk P, Bressler NM (2018) Repeatability and agreement of visual acuity using the ETDRS number chart, Landolt $\mathrm{C}$ chart, or ETDRS alphabet chart in eyes with or without sight-threatening diseases. JAMA Ophthalmol 136: 286-290. [Crossref]

28. Patel PJ, Chen FK, Rubin GS, Tufail A (2008) Intersession repeatability of visual acuity scores in age-related macular degeneration. Invest Ophthalmol Vis Sci 49: 4347-4352.

29. Aslam T, Mahmood S, Balaskas K, Patton N, Tanawade RG, et al. (2014) Repeatability of visual function measures in age-related macular degeneration. Graefes Arch Clin Exp Ophthalmol 252: 201-206. [Crossref]

Copyright: C2021 Claessens D. This is an open-access article distributed under the terms of the Creative Commons Attribution License, which permits unrestricted use, distribution, and reproduction in any medium, provided the original author and source are credited. 